\title{
PENGARUH MODEL PEMBELAJARAN BERDASARKAN MASALAH TERHADAP HASIL BELAJAR SISWA PADA MATERI POKOK LISTRIK DINAMIS KELAS X SMA RK DELI MURNI DELI TUA T.P 2013/2014
}

\author{
Rikardo Situmorang dan Togi Tampubolon \\ rikardo.situmorang17@gmail.com \\ Jurusan Fisika FMIPA Universitas Negeri Medan \\ Jalan Willem Iskandar Pasar V Medan, 20221
}

\begin{abstract}
This research is aimed to know the effect of problems based learning model to improve the achievement physics students in electrodynamics topic of class X Deli Murni Senior High School year 2013 / 2014. The research method is quasi experiment. The population all the students classes X Deli Murni Senior High School year 2013 / 2014 wich consist of 3 classes with population of 108 students. The sample determine by clusters random sampling by taking two classes. Class X-1 as a class experiment with 31 students and class X-2 as a class control with 31 students. The instrument used to know study result of the students is the test results of learning which essay test by 15 questions. Statistics analysis using t test with significant $\propto=0.05$ shows no influence of the application problems based learning model in improving the achievement of physics students on electrodynamics subject in class X Deli Murni Senior High School in the second semester year 2013/2014.
\end{abstract}

Keyword : Problem based Learning Models, Learning Outcome, Dinamis Electrical

\section{PENDAHULUAN}

Peran pendidikan sangat penting untuk menciptakan masyarakat yang cerdas, damai, terbuka dan demokratis. Sistem pendidikan nasional menyebutkan, bahwa pendidikan nasional berfungsi mengembangkan kemampuan dan membentuk watak serta peradaban bangsa bermartabat dalam rangka mencerdaskan kehidupan bangsa.

Pembelajaran adalah proses interaksi antara peserta didik dengan guru dan sumber belajar pada suatu lingkungan belajar
(Rusman, $2012 \quad$ :3). Dalam pembelajaran tugas guru yang paling utama adalah mengondisikan lingkungan agar menunjang terjadinya perubahan perilaku bagi peserta didik.

Soemosasmito (dalam Trianto, 2010 :20) menyatakan bahwa guru yang efektif adalah guru yang menemukan cara dan selalu berusaha agar anak didiknya terlibat secara tepat dalam suatu mata pelajaran dengan presentasi waktu belajar akademis yang tinggi dan pelajaran berjalan tanpa menggunakan teknik yang 
memaksa, negatif atau hukuman. Bidang studi sains fisika sebagai bagian dari Ilmu Pengetahuan Alam (IPA) merupakan objek mata pelajaran yang menarik dan lebih banyak memerlukan pemahaman dari pada penghafalan. Namun kenyataannya fisika sering dipandang sebagai suatu ilmu yang abstrak oleh siswa dengan teori dan soal-soal yang sulit. Berdasarkan hasil wawancara dengan salah seorang guru fisika di SMA RK Deli Murni Deli Tua, diperoleh bahwa hasil belajar siswa dalam seharihari masih rendah, siswa hanya mendapatkan hasil ujian dengan nilai yang masih dibawah 50 . Sedangkan KKM yang sudah ditentukan di sekolah adalah 70 . Berdasarkan angket yang diberikan kepada siswa juga menunjukkan bahwa minat belajar siswa terhadap pelajaran fisika masih kurang. Dari angket yang disebarkan kepada 34 orang siswa, $70,5 \%$ diantaranya menyatakan mata pelajaran fisika sulit dan kurang menarik. Hal ini juga dipengaruhi cara penyampaian materi pelajaran oleh guru di dalam kelas. Dari 34 orang siswa $76 \%$ bosan dengan pelajaran fisika karena guru hanya menyuruh siswa mencatat dan mengerjakan soalsoal. Proses pembelajaran di kelas hanya berpusat pada guru, sehingga siswa merasa jenuh. Sumber belajar yang digunakan siswa juga masih minim, karena siswa hanya menggunakan buku pelajaran yang diberikan sekolah sebagai sumber belajar.

Berdasarkan uraian di atas, jelaslah bahwa model atau metode mengajar mempengaruhi suasana dan hasil belajar siswa. Guru yang mengajar dengan model pembelajaran yang kurang menarik dapat menyebakan siswa menjadi bosan, pasif, dan tidak kreatif.

Setiap orang dapat berpikir dan memecahkan masalah, tetapi jelas ada perbedaan yang luas dalam kecakapan-kecakapan tersebut antara orang yang satu dengan yang lain. Perhatian yang utama ialah: apa yang dapat dilakukan untuk menolong siswa berpikir lebih terang dan memecahkan masalah secara lebih efisien (Slameto 2010:142).

Dari berbagai masalah yang dijumpai, dirasakan perlu adanya suatu pembelajaran yang membuat siswa aktif dalam kelas, melibatkan seluruh siswa dalam proses pembelajaran yang berorientasi pada pembelajaran yang berpusat pada siswa dengan mengangkat fenomena fisika yang lebih autentik dalam kehidupan sehari-hari. Serta yang paling penting adalah adanya suatu peningkatan hasil belajar siswa tersebut. Tentu dengan menggunakan model pembelajaran yang mendukung. Berdasarkan kenyataan tersebut, perlu diterapkan suatu model pembelajaran yang sesuai dan mampu meningkatkan aktivitas dan hasil belajar fisika siswa. Salah satu alternatif model pembelajaran yang memungkinkan diterapkan adalah model problem based learning (PBL). Model PBL merupakan pendekatan yang efektif untuk pengajaran proses berpikir tingkat tinggi (Trianto, 2010). Berpikir tingkat tinggi adalah kerja keras. Pembelajaran PBL dikembangkan untuk membantu siswa mengembangkan kemampuan berpikir, pemecahan masalah dan keterampilan intelektual, belajar berbagai peran orang dewasa melalui perlibatan mereka dalam 
pengalaman nyata dan menjadi pebelajar yang otonom dan mandiri.

\section{METODE PENELITIAN}

Penelitian ini dilaksanakan di SMA RK Deli Murni Deli Tua dengan alamat Jln. Lorong Nogio No. 117 Deli Tua. Penelitian dilaksanakan pada semester II T.A 2013/2014 tanggal 03 Mei 2014 hingga 31 Mei 2014 di kelas IX. Populasi dalam penelitian ini siswa kelas X SMA RK Deli Murni Deli Tua T.A 2013/2014 yang terdiri dari tiga kelas dengan jumlah populasi penelitian adalah 108 siswa. Dengan menggunakan teknik penarikan sampel kelas (cluster randam sampling satu kelas sebagai kelas eksperimen yaitu kelas IX-1 yang akan diberi perlakuan dengan model Pembelajaran Berdasarkan Masalah dan satu kelas sebagai kelas kontrol yaitu kelas IX-2 yang diberi perlakuan dengan menggunakan pembelajaran konvensional.

Variabel bebas dalam penelitian ini adalah pembelajaran dengan menggunakan model pembelajaran PBL dan model pembelajaran konvensional. Variabel terikat dalam penelitian ini adalah aktivitas dan hasil belajar fisika siswa pada materi pokok Listrik Dinamis.

Desain penelitian yang digunakan adalah desain Control Group Pretest-Posttest Design . Desain penelitian ini ditunjukkan pada Tabel di bawah.

Tabel Control Group PretestPosttest Design (Arikunto, 2012)

\begin{tabular}{|l|c|c|c|}
\hline Kelas & Pretes & Perlakuan & Postes \\
\hline Eksperimen & $O_{1}$ & $X_{1}$ & $O_{2}$ \\
\hline Kontrol & $O_{1}$ & $X_{2}$ & $O_{2}$ \\
\hline
\end{tabular}

Keterangan:

$O_{1}=$ (pretes) pemberian tes awal kepada kelas eksperimen dan kelas kontrol.

$\mathrm{O}_{2}=$ (postes) pemberian tes akhir kepada kelas eksperimen dan kelas kontrol.

$X_{1}=$ model pembelajaran problem based learning

$X_{2}=$ model pembelajaran konvensional.

Instrumen yang digunakan dalam penelitian ini adalah tes hasil belajar yang berbentuk uraian. Tes digunakan untuk mengukur penguasaan siswa terhadap materi yang diberikan dan melihat ketuntasan belajar. Tes disusun berbentuk essai tes sebanyak 15 soal. Untuk mengetahui kevalidan instrument, validitas tes yang digunakan adalah validitas isi (content validity). Instrumen tes telah divalidasi oleh 2 orang dosen fisika

Uji hipotesis yang menggunakan uji $t$ dilakukan dengan membandingkan rata-rata skor hasil belajar yang dicapai baik kelas eksperimen maupun kelas kontrol. Data yang diperoleh ditabulasikan kemudian dicari rataratanya. Sebelum dilakukan penganalisisan data, terlebih dahulu ditentukan skor masing-masing kelompok sampel lalu dilakukan pengolahan data dengan langkahlangkah sebagai berikut:

a) Menghitung nilai rata-rata dan simpangan baku

b) Uji normalitas

c) Uji homogenitas

d) Uji kesamaan rata-rata pretes

Hipotesis yang diuji berbentuk:

$\mathrm{H}_{\mathrm{o}}: \mu=\mu_{0}$ : Kemampuan awal siswa pada kelas eksperimen sama dengan kemampuan 
awal siswa pada kelas kontrol.

$\mathrm{H}_{\mathrm{a}}: \mu \neq \mu_{0}$ : Kemampuan awal siswa pada kelas eksperimen tidak sama dengan kemampuan awal siswa pada kelas kontrol.

e) Pengujian hipotesis

Hipotesis yang diuji berbentuk:

$$
\begin{aligned}
& \text { Ho }: \bar{\mu}=\overline{\mu_{0}} \\
& \text { Ha }: \bar{\mu}>\overline{\mu_{0}}
\end{aligned}
$$

Keterangan :

$$
\text { ( Sudjana, 2005) }
$$

$\bar{\mu}=\overline{\mu_{0}}$ : Tidak ada pengaruh model pembelajaran berbasis masalah terhadap hasil belajar siswa pada materi pokok listrik dinamis di SMA RK Deli Murni Deli Tua Tahun 2014

$\bar{\mu}>\overline{\mu_{0}}:$ Ada pengaruh model pembelajaran berbasis masalah terhadap hasil belajar siswa pada materi pokok listrik dinamis di SMA RK Deli Murni Deli Tua Tahun 2014.

\section{HASIL PENELITIAN DAN PEMBAHSASAN}

\section{a. Hasil penelitian}

Berdasarkan tes awal, diketahui bahwa nilai rata-rata pretes kelas ekspreimen sebesar 20,45 dan nilai rata-rata pretes kelas kontrol sebesar 19,29. Setelah dilakukan pengajaran, kedua kelas sampel yaitu kelas eksperimen dan kelas kontrol diberikan postes yang bertujuan untuk melihat kemampuan akhir belajar siswa pada kedua kelas tersebut diperoleh bahwa rata-rata postes kelas eksperimen 52,65 dan rata-rata postes kelas kontrol 47,55.
Uji normalitas data pretes dan postes kelas eksperimen dan kelas kontrol digunakan untuk mengetahui apakah data pretes dan postes berdustribusi normal dilakukan dengan menggunakan uji Liliefors.

Tabel 1. Hasil Uji Normalitas Kelas Eksperimen dan Kelas Kontrol

\begin{tabular}{|l|l|l|l|l|c|}
\hline \multirow{2}{*}{$\begin{array}{l}\text { Kelo } \\
\text { mpok }\end{array}$} & \multicolumn{2}{|c|}{$\begin{array}{c}\text { Data } \\
\text { Pretes }\end{array}$} & \multicolumn{2}{c|}{$\begin{array}{c}\text { Data } \\
\text { Postes }\end{array}$} & Kesi \\
\cline { 2 - 5 } & $L_{\text {hitun }}$ & $L_{\text {tabel }}$ & $L_{\text {hitun }}$ & $L_{\text {tabel }}$ & $\begin{array}{c}\text { mul } \\
\text { an }\end{array}$ \\
\hline $\begin{array}{l}\text { Ekspe } \\
\text { rimen }\end{array}$ & 0,1 & 0,1 & 0,1 & 0,1 & Norm \\
\hline $\begin{array}{l}\text { Kontr } \\
\text { ol }\end{array}$ & 0,1 & 59 & 45 & 59 & al \\
\hline
\end{tabular}

Berdasarkan Tabel 1 menunjukkan bahwa $\mathrm{L}_{\text {hitung }}<\mathrm{L}_{\text {Tabel }}$ maka data pretes dan postes kedua kelompok sampel berdistribusi normal yang artinya bahwa sebaran nilai pada kelas eksperimen dan kelas kontrol sama.

Uji Homogenitas dilakukan untuk mengetahui apakah sampel yang diambil varians homogen atau tidak menggunakan uji kesamaan

\begin{tabular}{|c|c|c|c|c|}
\hline \multicolumn{5}{|c|}{ Pretes } \\
\hline $\begin{array}{c}\text { Data } \\
\text { Pretes }\end{array}$ & $\begin{array}{c}\text { Varia } \\
\text { ns }\end{array}$ & $\mathrm{F}_{\text {hit }}$ & $\mathrm{F}_{\mathrm{tab}}$ & $\begin{array}{c}\text { Kesimp } \\
\text { ulan }\end{array}$ \\
\hline $\begin{array}{l}\text { Varians } \\
\text { terbesar }\end{array}$ & 52,946 & 1117 & 1,8 & Homog \\
\hline $\begin{array}{l}\text { Varians } \\
\text { terkecil }\end{array}$ & 47,489 & $1,11 /$ & 4 & \\
\hline
\end{tabular}
dua varians.

Tabel 2 Uji Homogenitas Data

Tabel 2 menunjukkan bahwa $\mathrm{F}_{\text {hitung }}<\mathrm{F}_{\text {tabel }}$ yaitu $1,117<1,84$ dengan $a=0,05$, maka dapat disimpulkan bahwa data pretes homogen. 
Untuk kemampuan awal siswa pada kedua kelas sampel digunakan uji kesamaan rata-rata dengan uji t dua pihak.

$\mathrm{H}_{0}: \mu_{1}=\mu_{2}$ : Kemampuan awal siswa pada kelas eksperimen sama dengan kemampuan awal siswa pada kelas kontrol.

$\mathrm{H}_{\mathrm{a}}: \mu_{1} \neq \mu_{2}$ : Kemampuan awal siswa pada kelas eksperimen tidak sama dengan kemampuan awal siswa pada kelas kontrol.

Tabel 3. Ringkasan perhitungan uji $\mathrm{t}$ dua pihak data pretes

\begin{tabular}{|l|c|c|c|c|}
\hline $\begin{array}{c}\text { Data } \\
\text { Pretes }\end{array}$ & $\begin{array}{c}\text { Rata- } \\
\text { rata }\end{array}$ & thit & t $_{\text {tab }}$ & $\begin{array}{c}\text { Kesimp } \\
\text { ulan }\end{array}$ \\
\hline $\begin{array}{l}\text { Eksprim } \\
\text { en }\end{array}$ & 20,45 & 0,645 & 2 & $\begin{array}{c}\text { Kemam } \\
\text { puan } \\
\text { awal } \\
\text { siswa } \\
\text { Kama }\end{array}$ \\
\hline
\end{tabular}

Berdasarkan tabel 3 diperoleh bahwa untuk nilai pretes thitung $<$ tabel yaitu $0,645<2,00$ maka $\mathrm{H}_{0}$ diterima sehingga dapat disimpulkan bahwa kemampuan awal siswa pada kelas eksperimen sama dengan kemampuan awal siswa pada kelas kontrol.

Untuk menguji hipotesis digunakan uji t satu pihak.

Tabel 4. Ringkasan perhitungan uji

\begin{tabular}{|l|l|l|l|l|}
\multicolumn{5}{|c}{ t data postes } \\
\hline Kelas & $\begin{array}{l}\text { Rata } \\
\text {-rata }\end{array}$ & thit & tab & $\begin{array}{l}\text { Kesimpula } \\
\mathrm{n}\end{array}$ \\
\hline $\begin{array}{l}\text { Eksperime } \\
\mathrm{n}\end{array}$ & $\begin{array}{l}52,6 \\
5\end{array}$ & 1,8 & $\begin{array}{l}1,6 \\
7\end{array}$ & $\begin{array}{l}\text { Ada } \\
\text { perbedaan } \\
\text { yang } \\
\text { Signifikan }\end{array}$ \\
\hline
\end{tabular}

Berdasarkan Tabel 4, kelas eksperimen yang diajarkan dengan model PBL memperoleh nilai ratarata hasil belajar adalah 52,65 dan kelas kontrol yang diajarkan dengan model konvensional memperoleh hasil belajar dengan rata-rata 47,55. Data di atas menunjukkan bahwa $t_{\text {hitung }}>\mathrm{t}_{\text {tabel }}(1,82>1,67)$, sehingga dapat disimpulkan bahwa ada pengaruh model problem based learning (PBL) yang signifikan terhadap hasil belajar siswa pada materi listrik dinamis kelas X SMA RK Deli Murni Deli Tua.

Observasi bertujuan untuk mengamati aktivitas belajar siswa selama pembelajaran dengan model pembelajaran Problem Based Learning. Observasi dilakukan selama kegiatan belajar mengajar yang terdiri dari tiga kali pertemuan. Perkembangan aktivitas siswa di kelas eksperimen mengalami peningkatan selama menerima pembelajaran dengan model pembelajaran Problem Based Learning. Pada pertemuan I diperoleh rata-rata aktivitas siswa 57,35 pada pertemuan II diperoleh rata-rata aktivitas 60,40 dan pada pertemuan III diperoleh rata-rata aktivitas 68,46. Peningkatan aktivitas belajar siswa dari pertemuan I sampai pertemuan III dengan rata-rata nilai seluruhnya adalah 62,07 dengan kriteria penilaian aktif.

\section{b. Pembahasan}

Hasil penelitian menunjukkan bahwa ada pengaruh menggunakan model pembelajaran Problem Based Learning untuk meningkatkan hasil belajar fisika siswa pada materi pokok Listrik Dinamis kelas X semester II SMA RK Deli Murni Deli Tua T.P 2013/2014. Hal ini diperkuat dengan perolehan nilai rata-rata pretes siswa di kelas eksperimen sebesar 20,45 dengan standar deviasi 8,884 
dan nilai rata-rata postes sebesar 52,65 dengan standar deviasi 19,889. Sedangkan di kelas kontrol diperoleh nilai rata-rata pretes siswa sebesar 19,29 dengan standar deviasi 7,276 dan nilai rata-rata postes sebesar 47,55 dengan standar deviasi 12,359 dan diperoleh thitung $>$ $t_{\text {tabel }}=(1,82>1,67)$ maka dapat disimpulkan bahwa $\mathrm{H}_{0}$ ditolak dan $\mathrm{H}_{\mathrm{a}}$ diterima.

Berdasarkan data nilai pretest dan postest beserta nilai aktivitas belajar siswa pada kelas eksperimen diperoleh data seperti gambar:

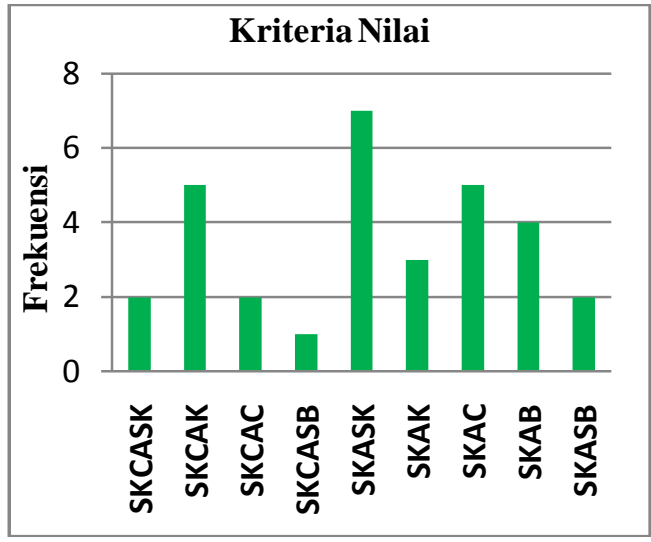

Gambar 1. Diagram batang kategori nilai pretes, aktivitas dan postes

Keterangan :

SKASB : sangat kurang, aktif dan sangat baik

SKAB : sangat kurang, aktif dan baik

SKAC : sangat kurang, aktif dan cukup

SKAK : sangat kurang, aktif dan kurang

SKASK : sangat kurang, aktif dan sangat kurang

SKCASB : sangat kurang, cukup aktif dan sangat baik

SKCAC : sangat kurang, cukup aktif dan cukup
SKCAK : sangat kurang, cukup aktif dan kurang

SKCASK : sangat kurang, cukup aktif dan sangat kurang

Berdasarkan analisis grafik, diperoleh persamaan linier $\mathrm{y}=\mathrm{ax}+\mathrm{b} \quad$ yg memiliki nilai a yang menyatakan kemiringan garis. Jika dilihat dari grafik, nilai a pada $\mathrm{y}_{\text {post }}=0,215 \mathrm{x}+50,42$ lebih besar dibandingkan dengan nilai a pada $\mathrm{y}_{\text {pre }}=0,042 \mathrm{x}+19,96$. Nilai a pada persamaan linier pretes $\left(\mathrm{a}_{\text {pre }}\right)$ menjadi acuan kriteria dalam menentukan berpengaruh atau tidaknya nilai aktivitas. Adapun kriterianya adalah sebagai berikut: $a_{\text {post }}>a_{\text {pre }}$ : nilai aktivitas mempengaruhi hasil belajar (nilai postes)

$a_{\text {post }}<a_{\text {pre }}:$ nilai aktivitas tidak mempengaruhi hasil belajar (nilai postes)

Hal ini menunjukkan $a_{\text {post }}>$ apre yang berarti nilai aktivitas mempengaruhi hasil belajar (nilai postes).

Persamaan linear untuk nilai post test adalah $\mathrm{y}_{\text {post }}=1,215 \mathrm{x}+34,42$ lebih kecil dibandingkan dengan nilai a pada $\mathrm{y}_{\text {pre }}=0,758 \mathrm{x}+8,503$

Hal ini menunjukkan $a_{\text {post }}>$ apre yang berarti nilai aktivitas mempengaruhi hasil belajar (nilai postes). Pelaksanaan model pembelajaran dikatakan berhasil apabila nilai a postes minimal sama dengan nilai a pretes.

Data nilai siswa perkelompok dapat disusun berdasarkan urutan nilai rata-rata perkelompok dari urutan nilai rata-rata pretes terendah ke nilai rata-rata tertinggi. Persamaan untuk nilai pretes, aktivitas dan postes adalah 
$\mathrm{y}_{\text {post }}=0,441 \mathrm{x}+46,81 \quad$ lebih kecil dibandingkan dengan nilai a pada $\mathrm{y}_{\text {pre }}=0,240 \mathrm{x}+16,8 \quad \mathrm{Hal} \quad$ ini menunjukkan apost $>$ apre yang berarti nilai aktivitas mempengaruhi hasil belajar (nilai postes).

Dalam penelitian ini pembagian kelompok sudah dapat dikatakan berhasil karena terbukti bahwa aktivitas setiap siswa pada kelompok mempengaruhi peningkatan nilai postes. Agar aktivitas kelompok lebih berpengaruh terhadap hasil belajar disarankan agar membuat perencanaan yang lebih baik pada pengorganisasian kelompok.

Dalam penelitian ini kelebihan yang dapat diberikan dengan menggunakan model pembelajaran Problem Based Learning adalah meningkatkan kemampuan siswa dalam pemecahan masalah dan menjadi pebelajar yang otonom dan mandiri. Langkah-langkah pembelajaran pada model pembelajaran Problem Based Learning mendorong siswa untuk lebih aktif di dalam kelas. Misalnya pada saat mengerjakan LKS, siswa dibagi ke dalam kelompok yang hanya beranggotakan 6 sampai 7 orang siswa, mengerjakan LKS selama 30 menit, kemudian mempresentasikan hasil diskusi kepada teman-teman yang lain. Hal ini mendorong siswa untuk lebih berpartisipasi dalam kerja kelompoknya.

Walaupun penggunaan model pembelajaran berbasis masalah dapat meningkatkan hasil belajar dan aktivitas siswa, tetapi selama pembelajaran masih ada kendala yang dihadapi peneliti yaitu, ketika menyajikan fenomena atau demostrasi atau cerita apa yang bisa memunculkan masalah yang akan dipecahkan saat proses pembelajaran berlangsung. Hasil penilaian aktivitas telah dapat memberikan gambaran meningkatkan hasil belajar seperti yang diharapkan, dalam hal ini masih terdapat kelemahan yang terjadi dapat disebabkan oleh penjelasan peneliti yang kurang memadai kepada observer dan banyaknya siswa dalam setiap kelompok yang harus diamati observer .

Selain itu, kesulitan yang dihadapi peneliti yaitu kurang terbiasanya siswa melakukan penyelidikan individu dan kelompok sehingga peneliti memerlukan banyak waktu dalam membimbing pelaksanaan penyelidikan. Pelaksanaan model pembelajaran berbasis masalah dapat berjalan baik dilihat dari nilai rata-rata pretes < nilai rata-rata postes. Namun masih banyak yang harus dibenahi, baik dari segi perencanaan maupun dari segi pelaksanaannya.

\section{KESIMPULAN DAN SARAN}

\section{Kesimpulan}

Berdasarkan hasil penelitian dapat disimpulkan bahwa hasil pengujian hipotesis dengan uji-t satu pihak diperoleh bahwa ada pengaruh model pembelajaran berbasis masalah terhadap hasil belajar siswa pada materi pokok listrik dinamis di SMA RK Deli Murni Deli Tua Tahun 2014 dengan peningkatan aktivitas belajar dalam kategori aktif. 


\section{Saran}

Saran yang dapat peneliti ajukan berdasarkan pembahasan adalah (1) Orientasi siswa pada masalah dapat dilakukan dengan bantuan video atau rekaman fenomena atau peristiwa nyata yang dapat memunculkan masalah dan dapat menarik minat dan motivasi siswa untuk terlibat dalam pemecahan masalah. (2) Pemilihan masalah dan penggunnaan soal yang digunakan lebih diperhatikan. (3) Implementasi tahapan model pembelajaran berdasarkan masalah lebih ditingkatkan supaya setiap deskriptor aktivitas dapat tercapai dengan baik dan aktivitas dapat mempengaruhi hasil belajar siswa.

\section{DAFTAR PUSTAKA}

Arikunto,S., (2012), Dasar-Dasar Evaluasi Pendidikan, Bumi Aksara, Jakarta.

Hermanto, 2013. Pengaruh Model Pembelajaran Berbasis Masalah (Problem Based Learning) Terhadap Hasil Belajar Siswa Pada Materi Pokok Listrik Dinamis Kelas $\mathrm{X}$ Semester II SMA N 1 Sei Bingai T.P. 2012/2013. Skripsi. Medan : FMIPA Unimed.

Pohan, 2013. Pengaruh Model Pembelajaran Berbasis Masalah (Problem Based Learning) Terhadap Hasil Belajar Siswa Pada Materi Pokok Listrik Dinamis Kelas IX SMP N 5 Pematang Siantar T.P. 2012/2013. Skripsi. Medan : FMIPA Unimed.

Rusman, (2012), Model-Model Pembelajaran, Rajagrafindo Persada, Jakarta.
Slameto, (2010), Belajar dan Faktorfaktor yang Mempengaruhinya, Rineka Cipta, Jakarta.

Sudjana, (2005), Metode Statistika, Tarsito, Bandung.

Trianto, (2010), Mendesain Model Pembelajaran Inovatif Progresif, Kencana, Jakarta. 